DOI 10. 18307/2021. 0404

(C) 2021 by Journal of Lake Sciences

\title{
内陆水体好氧甲烷氧化过程研究进展”
}

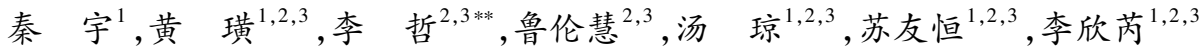 \\ ( 1 : 重庆交通大学水利水运工程教育部重点实验室,重庆 400074) \\ (2: 中国科学院重庆绿色智能技术研究院,重庆 400714) \\ (3: 中国科学院大学重庆学院, 重庆 400714)
}

\begin{abstract}
摘 要: 内陆水体是全球碳循环的关键组成部分, 是大气中甲烷 $\left(\mathrm{CH}_{4}\right)$ 的重要来源, 每年从内陆淡水与自然湿地排放进 人大气的 $\mathrm{CH}_{4}$ 约为 $185 \sim 357 \mathrm{Tg} / \mathrm{a}$. 通常, 内陆水体中 $\mathrm{CH}_{4}$ 主要由分布于水层底部的厌氧区或沉积层内的产甲烷菌介导产 生, 其向水层表面传输的过程中易被甲烷氧化菌所氧化. 甲烷氧化菌可分为好氧甲烷氧化菌和厌氧甲烷氧化菌,有氧条 件下, 由好氧甲烷氧化菌介导的好氧甲烷氧化过程是水体中甲烷氧化过程的主要形式, 湖泊底部产生的 $\mathrm{CH}_{4}$ 总量中约有 $99 \%$ 可以被上覆水体中的好氧甲烷氧化过程所消耗. 本文收集文献综合分析阐明,好氧甲烷氧化过程是由水环境因子、水 文条件以及不同内陆水体的生态系统特征共同调控,同时也表现在了好氧甲烷氧化菌的生境偏好上. 复杂的调控过程构 建了内陆水体向大气输送 $\mathrm{CH}_{4}$ 的动态平衡,并最终反映在内陆水体对全球 $\mathrm{CH}_{4}$ 循环、碳循环作出的贡献上.
\end{abstract}

关键词: 内陆水体;好氧甲烷氧化菌;好氧甲烷氧化速率;生境偏好;水体类型

\section{Research progress of aerobic methane oxidation process in inland waters *}

\author{
Qin $\mathrm{Yu}^{1}$, Huang Huang ${ }^{1,2,3}$, Li Zhe ${ }^{2,3 * *}$, Lu Lunhui ${ }^{2,3}$, Tang Qiong ${ }^{1,2,3}$, Su Youheng ${ }^{1,2,3}$ \& Li Xinrui ${ }^{1,2,3}$ \\ (1: Key Laboratory of Water Conservancy and Water Transportatiom Engineering, Ministry of Education, Chongqing Jiaotong \\ University, Chongqing 400074, P.R.China) \\ (2: Chongqing Institute of Green and Intelligent Technology, Chinese Academy of Sciences, Chongqing 400714, P.R.China) \\ (3: Chongqing School, University of Chinese Academy of Sciences, Chongqing 400714, P.R.China)
}

\begin{abstract}
Inland waters are important parts in global carbon biogeochemial cycles. It is also one of the main sources of methane. Annual emissions of $\mathrm{CH}_{4}$ from inland freshwaters and natural wetlands into the atmosphere is $185-357 \mathrm{Tg} / \mathrm{a}$. Methane is mainly produced by the reactions between bottom organic sediments and methanogenic bacteria in anoxic zone of inland waters. Methane is then consumed by methane-oxidizing bacteria during its upsurge to surface water. Methane-oxidizing bacteria can be divided into aerobic methane-oxidizing bacteria and anaerobic methane-oxidizing bacteria. Under aerobic conditions, the aerobic methane oxidation process mediated by aerobic methane-oxidizing bacteria is the main form of methane oxidation process in water, and about $99 \%$ of the total $\mathrm{CH}_{4}$ produced at the bottom of the lake can be consumed by the aerobic methane oxidation process in the overlying water. According to the comprehensive analysis of literature collected in this paper, the process of aerobic methane oxidation is controlled by water environmental factors, hydrological conditions and ecosystem characteristics of different inland waters, and also reflected in the habitat preference of aerobic methane-oxidizing bacteria. The complex regulation process constructs the dynamic balance of the total amount of $\mathrm{CH}_{4}$ transported from inland waters to the atmosphere, which is reflected in the contribution of inland waters to the global $\mathrm{CH}_{4}$ cycle and carbon cycle.
\end{abstract}

Keywords: Inland waters; aerobic methane-oxidizing bacteria; aerobic methane oxidation rate; habitat preference; type of water

甲烷 $\left(\mathrm{CH}_{4}\right)$ 是大气里的气体成分之一, 对气候会产生强烈的温室效应, 是仅次于二氧化碳 $\left(\mathrm{CO}_{2}\right)$ 的第二

* 2020-06-30 收稿; 2020-10-16 收修改稿.

国家自然科学基金项目 (51861125204) 资助.

** 通信作者; E-mail:lizhe@ cigit.ac.cn. 
重要温室气体 (greenhouse gas, $\mathrm{GHG})^{[1]}$. 自 17 世纪以来, 快速增长的人类活动使得 $\mathrm{CH}_{4}$ 排放量快速增加 ${ }^{[1]}$, 目前全球大气 $\mathrm{CH}_{4}$ 平均浓度已达 $1.87 \mu \mathrm{atm}^{[2]}$, 且近 10 年其浓度年均增速为 $7.1 \times 10^{-3} \mu \mathrm{atm} / \mathrm{a}^{[2]}$, 呈现出增速 加快趋势, $\mathrm{CH}_{4}$ 对全球温室效应的影响在逐步扩大. 内陆水体 (inland waters) 主要包括湖泊、河流、水库和浅 水池塘等, 通常情况下不包含自然湿地 (natural wetland). 尽管内陆水体占地球水生态系统总面积很小, 但它 们仍显著影响着全球碳收支平衡, 是全球大气温室气体的重要贡献者 ${ }^{[3-4]}$.

水体中 $\mathrm{CH}_{4}$ 浓度随时间和深度的变化是 $\mathrm{CH}_{4}$ 产生与消耗平衡的最终结果 $\left(\mathrm{CH}_{4}\right.$ 动态平衡). 传统认为, $\mathrm{CH}_{4}$ 在水体底部或沉积层严格厌氧环境下由产甲烷古菌产生并释放进人水体. 产生的 $\mathrm{CH}_{4}$ 向上覆水运输过 程中易被甲烷氧化菌大量利用与消耗, 从而明显减少水一气界面的 $\mathrm{CH}_{4}$ 扩散通量, 最终未被消耗的 $\mathrm{CH}_{4}$ 释放 进人大气 ${ }^{[5]}$. 甲烷氧化菌 (methane-oxidizing bacteria, MOB) 由氧是否作为电子受体划分为好氧甲烷氧化菌和 厌氧甲烷氧化菌两类. 内陆水体中, $\mathrm{CH}_{4}$ 的氧化过程主要是由好氧甲烷氧化菌介导的, 而这一氧化过程可能 会消耗尽全部的水体 $\mathrm{CH}_{4}$ 产量 ${ }^{[6-8]}$. 在好氧甲烷氧化菌影响因素方面, 好氧甲烷氧化过程除自身生物生境偏 好的影响外也会受到一系列非生物因素影响, 并最终影响内陆水体中 $\mathrm{CH}_{4}$ 收支. 本文尝试对当前好氧甲烷 氧化过程的微生物生理生态、全球范围内内陆水体好氧甲烷氧化速率、主要影响因素等进行汇总整理, 并从 生物因素、非生物因素两个方面, 对当前内陆水体好氧甲烷氧化研究进展进行探讨.

\section{1 好氧甲烷氧化菌作用机理及类别}

好氧甲烷氧化菌是甲基营养细菌的一个分支, MOB 广泛分布于各种水体环境中 ${ }^{[9]}$. 其中甲烷单加氧酶 (Methane monooxygenase, MMO), 包括可溶性甲烷单加氧化酶 (soluble MMO, sMMO) 和颗粒性甲烷单加氧化 酶 (particulate MMO, $\mathrm{pMMO}$ ), 是推动微生物代谢层面上 $\mathrm{CH}_{4}$ 氧化的关键 ${ }^{[10-12]}$. 两类 $\mathrm{MMO}$ 会催化氧化 $\mathrm{CH}_{4}$ 为 甲醇 $\left(\mathrm{CH}_{3} \mathrm{OH}\right), \mathrm{CH}_{3} \mathrm{OH}$ 会被进一步氧化为甲醛 $(\mathrm{HCHO})$. 而后 $\mathrm{HCHO}$ 通过戊糖一磷酸核酮糖 ( RuMP) 途径 或者丝氨酸 (Serine) 途径进一步反应被转化为甲酸或者细胞质,最终所有的反应会将 $\mathrm{CH}_{4}$ 反应成为 $\mathrm{CO}_{2}$, 好 氧甲烷氧化菌具体代谢过程如图 1 所示. 目前普遍认为, $\mathrm{sMMO}$ 仅存在于少数的甲烷氧化菌中, $\mathrm{pMMO}$ 存在 于几乎所有已知的甲烷氧化菌中 ${ }^{[13-14]}$. 最初, 基于生理、形态、超微结构和化学分类学特征, 好氧甲烷氧化菌 被分为 Type I 型与 Type II 型两大类. Type I 型好氧甲烷氧化菌特征是: ( i ) 以 RuMP 作为反应途径去同 化产生的甲醛; ( ii ) 细胞内主要含有 16-C 脂肪酸; ( iii ) 胞内膜形态呈现为束状分布; Type II 型好氧甲烷氧 化菌特征是 ( i ) 以 Serine 作为反应途径去同化产生的甲醛; ( ii ) 细胞内的优势脂肪酸为 $18-\mathrm{C}$ 脂肪酸; ( iii ) 胞内膜分布在菌内细胞壁的周围 ${ }^{[15]}$. 对 $16 \mathrm{~S} \mathrm{rRNA}$ 基因序列的系统进化分析也证实了上述分类, 进一步将 Type I 型和 Type II 型好氧甲烷氧化菌分别归于 $\gamma$-变形菌和 $\alpha$-变形菌 ${ }^{[16]}$.

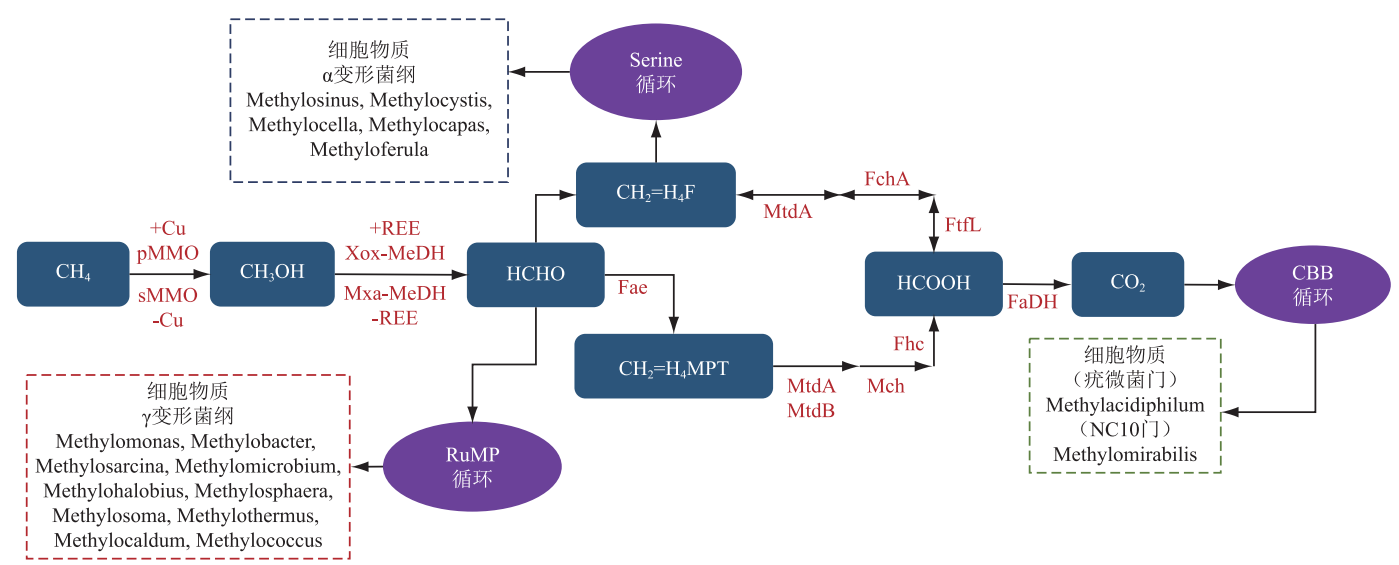

图 1 好氧甲烷氧化菌代谢过程化学反应路径

Fig. 1 Chemical reaction path in metabolic process of aerobic methane-oxidizing bacteria 
随研究深人, 好氧甲烷氧化菌的分类系统更加细化. 目前, $\gamma$-变形菌纲 (Gammaproteobacteria, 约 16 属, 也称之为 Type I 型). $\alpha$-变形菌纲 (Alphaproteobacteria, 约 6 属, Type II 型) 被划分为 IIa 型和 IIb 型好氧甲烷 氧化菌 ${ }^{[17-18]} ; \gamma$-变形菌 (Type I 型) 的划分方式仍然存在一定分歧,一般的划分方式是将 Methylococcaceae 科 划分为 Ia 型和 Ib 型, Methylothermaceae 科划分为 Ic 型好氧甲烷氧化菌 ${ }^{[19]}$. 在 2007 年的 Nature 报道的 3 株 极端嗜酸 $(\mathrm{pH}<2)$ 的好氧甲烷氧化菌, 它们均属于疮微菌门 (Verrucomicrobia, 目前已知 2 属), 这种新发现细 菌被划分为 III型好氧甲烷氧化菌 ${ }^{[20-22]}$, 而其相应的循环途径 ( CBB ) 是将 $\mathrm{CO}_{2}$ 作为碳源供给自己的代谢活 动, 且这种 $\mathrm{CO}_{2}$ 的利用除从自身产出的也可以利用水环境中的, 这与 $\mathrm{NC} 10$ 门厌氧甲烷氧化菌的代谢过程是 相同的. 现阶段, 内陆水体中好氧甲烷氧化菌研究大多围绕 $\gamma$-变形菌和 $\alpha$-变形菌的生态位分化展开. 在此基 础上, 好氧甲烷氧化菌系统分类研究则更加强化了对菌种的地理空间分布及生境偏好研究, 这为内陆水体 中 $\mathrm{CH}_{4}$ 氧化的分析过程提供新思路.

\section{2 内陆水体好氧甲烷氧化菌生境偏好}

好氧甲烷氧化菌最早发现于 20 世纪初, 但直到 1970s, 才对其进行了广泛的分离和鉴定, 以便进行详细 的生理分析. 大多数已知的好氧甲烷氧化菌在中等酸碱度 $(\mathrm{pH} 5 \sim 8)$ 以及温度范围 $\left(20 \sim 35^{\circ} \mathrm{C}\right)$ 下生长最好, 同时随着生物化学进步嗜冷 (生长 $\left.<15^{\circ} \mathrm{C}\right) 、$ 、嗜热 (生长 $>40^{\circ} \mathrm{C}$ )、嗜碱 $(\mathrm{pH}>9.0)$ 和嗜酸 $(\mathrm{pH}<5)$ 的特殊好氧甲 烷氧化菌在极端水环境中被逐渐分离出来 ${ }^{[23-24]}$. 对于非极端条件下内陆水体而言, 温度和溶解氧 (DO) 浓 度、 $\mathrm{CH}_{4}$ 浓度联系紧密, 三者构成了好氧甲烷氧化菌活性变化与代谢区域的直接影响因素, 因而研究好氧甲 烷氧化菌生境时往往伴随着三大影响因素的研究 ${ }^{[25-28]}$.

内陆水体中 Type I 型好氧甲烷氧化菌通常被认为是 $\mathrm{CH}_{4}$ 氧化的“先锋队”. 在一些水体表层沉积物中 Type I 型好氧甲烷氧化菌的 $p m o A$ 基因拷贝量甚至比 Type II 型好氧甲烷氧化菌高 $1 \sim 2$ 个数量级 ${ }^{[29-30]}$. Type II 型好氧甲烷氧化菌则更像是 $\mathrm{CH}_{4}$ 氧化的“常备军”. 尽管 Type II 型好氧甲烷氧化菌不常占优, 但却呈现出 对生境胁迫 (温度、DO、pH 等) 的高耐受性, 具有更强的 “弹性”或稳定性以应对生境变化 ${ }^{[31]}$. 故有研究者倾 向于将 Type I 型好氧甲烷氧化菌的生存策略归纳为 “ C 型” (竞争者), 而 Type II 型好氧甲烷氧化菌的生存 策略则是更接近于 “ $\mathrm{S}$ 型” (胁迫耐受者) ${ }^{[32]}$.

\section{1 好氧甲烷氧化菌的温度偏好}

Shivaji 等 ${ }^{[33]}$ 认为每种类型的好氧甲烷氧化菌都有适宜生长的温度, 温度的变化也可能导致好氧甲烷氧 化菌群落的结构发生变化, 同时有研究表明降水与温度的相互作用对部分好氧甲烷氧化菌丰度带来明显变 化 ${ }^{[34]}$. 同时温度也会影响好氧甲烷氧化菌的酶活性, 如羟丙酮酸还原酶、已糖磷酸合酶、甲酸脱氢酶和核糖 二磷酸羧化酶活性等 ${ }^{[35]}$. 尽管 Type I 型好氧甲烷氧化菌和 Type II 型好氧甲烷氧化菌在较宽的温度范围内 都具有活性 ${ }^{[36]}$, 但通常情况下, Type II 型好氧甲烷氧化菌在高于 $15^{\circ} \mathrm{C}$ 的温度下生长较好 ${ }^{[37-38]}$, Type I 型好 氧甲烷氧化菌则在低温 $\left(5 \sim 15^{\circ} \mathrm{C}\right)$ 下更有利 ${ }^{[24]}$, 例如在南极分离的 Methylomonas scandinavica 就属于耐低温 菌 ${ }^{[39-40]}$. 但 Type I 型好氧甲烷氧化菌不止一个属种可以适应高温环境, 其中 Methylococcus 和 Methylocaldum 就是一类特殊的耐热菌, 而 Type I 型中的 Methylothermus thermalis 最高活性下的温度超过了 $55^{\circ} \mathrm{C}^{[41]}$. 而拥 有高耐受性的 Type II 型好氧甲烷氧化菌也存在耐低温的菌种 ${ }^{[42]}$.

\section{2 好氧甲烷氧化菌的溶解氧浓度偏好}

内陆水体不同类别的好氧甲烷氧化菌群落分布会受到 DO 浓度的明显影响, 有研究发现分层明显的水 体中, 地表水和中层水主要由 Type II 型好氧甲烷氧化菌主导, 而 Type I 型好氧甲烷氧化菌在深水中占主 导 ${ }^{[43]}$. 在内陆水体中, 所有好氧甲烷氧化菌很少出现在水体表层, 这是因为水体表层过高的 DO 浓度会抑制 好氧甲烷氧化菌活性, 所以通常好氧甲烷氧化菌丰度最高处发生在沉积物或水体内的好氧一厌氧交界处, 即 $\mathrm{DO}$ 浓度和 $\mathrm{CH}_{4}$ 浓度梯度相交处 ${ }^{[4]}$. 然而 Pavin 湖中的缺氧层中检测到了 Methylobacter 属好氧甲烷氧化

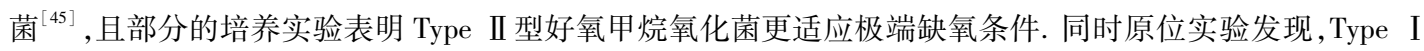
型好氧甲烷氧化菌在极端缺氧环境中有不同属的存在. 例如 Kalyuzhnaya 等 ${ }^{[46-48]}$ 研究发现, Methylobacter alcaliphilum strain 20Z 在 DO 含量小于 5\% 时, 好氧甲烷氧化菌的活性会受抑制使反应速率下降, Methylobacter trichosporium $\mathrm{OB} 3 \mathrm{~b}$ 与 Methylobacter parvus OBBP 对于 DO 含量变化响应不明显, 而 Methylobacter trichosporium 
最适 DO 含量在 1.6\% 18\% 之间. 这一系列研究表明好氧甲烷氧化菌, 特别是 Methylobacter 属在低 DO 含量 条件下具有更高的活性. 而从生物因子角度解释 ${ }^{[49]}$, 好氧甲烷氧化菌产生活性氧产物 (包括超氧阴离子自 由基、过氧化氢和羟基自由基) 作为代谢过程中的副产物, 这会对细胞结构造成氧化损伤, 因此大量好氧甲 烷氧化菌生存于 DO 浓度更低且 $\mathrm{CH}_{4}$ 浓度更高的水体深层, 既满足了基本的氧需求也满足反应底物浓度的 需求. 而在缺氧情况下, Oswald 等 ${ }^{[28]}$ 通过放射性示踪实验揭示了 $\mathrm{CH}_{4}$ 氧化的光诱导作用下, 看似缺氧的水层 存在 DO, 并且在同一区域发现了 Methylobacter 属的好氧甲烷氧化菌 ${ }^{[50]}$. 而在瑞士 LagodiCadagno 湖, 研究者 发现光穿透好氧区到达缺氧区, 好氧甲烷氧化菌可以利用藻类光合作用所产生的 DO 在缺氧区内进行好氧 甲烷氧化过程 ${ }^{[51]}$. 这意味着光通过水中生物进行隐性光合作用, 可以扩大适合好氧甲烷氧化菌的氧化带, 从而推动好氧甲烷氧化菌的代谢反应.

\section{3 好氧甲烷氧化菌的甲烷浓度偏好}

好氧甲烷氧化菌的代谢过程活性也会受限于 $\mathrm{CH}_{4}$ 浓度, 其浓度和可利用性是影响代谢过程的关键因素 之一, 低 $\mathrm{CH}_{4}$ 浓度会导致整体的好氧甲烷氧化菌氧化活性下降 ${ }^{[52-53]}$. Type I 型好氧甲烷氧化菌对 $\mathrm{CH}_{4}$ 浓度 变化响应较 Type II 型好氧甲烷氧化菌明显 ${ }^{[54]}$, 在相对适宜的水环境条件下占优. 而 Crevecoeur 等 ${ }^{[9]}$ 在加拿 大魁北克自然水域的研究中发现 Type II 型好氧甲烷氧化菌在极端的 $\mathrm{CH}_{4}$ 浓度下 (过高或过低) 倾向于占优. 其原因可能是 Type II 型好氧甲烷氧化菌对生境胁迫的高耐受性, 在极端 $\mathrm{CH}_{4}$ 浓度下尤为重要 ${ }^{\left[{ }^{[31}\right.}$. 因而 Type I 型好氧甲烷氧化菌可能在支持其快速生长的稳点环境中占主导地位, 而 Type II 型好氧甲烷氧化菌则更能 承受环境的波动影响,并逐渐在极端环境下占主导地位.

\section{4 好氧甲烷氧化菌的其他环境因子偏好}

好氧甲烷氧化菌本身被认为是低速慢生长的细菌 ${ }^{[55]}$, 通常需要几周时间实现倍增 ${ }^{[56]}$. 有研究发现多个 相似湖泊的对比下, $\mathrm{PO}_{4}^{3-}$ 浓度高的湖泊其好氧甲烷氧化菌丰度也更高 ${ }^{[57]}$. 这是由于所有生物都需要磷来进 行细胞分裂、能量转化和细胞生命维持, 因此好氧甲烷氧化菌可能会因异养细菌的快速生长而无法竞争营 养, 而当细菌生长竞争激烈的情况下更高的 $\mathrm{PO}_{4}^{3-}$ 浓度可以使好氧甲烷氧化菌不受磷的限制. 除了磷和微生 物群落之间的相互作用以外, 其他营养盐可能进一步增强了好氧甲烷氧化菌的生长和影响随后的 $\mathrm{CH}_{4}$ 氧化. 因具备固氮功能或具有好氧反硝化能力, 部分好氧甲烷氧化菌同 $N$ 循环亦具有密切关联性 ${ }^{[58-59]}$, 但无机氮 浓度 $\left(\mathrm{NH}_{4}^{+}\right.$或 $\left.\mathrm{NO}_{3}^{-}\right)$一直以来对于 $\mathrm{CH}_{4}$ 氧化的影响是矛盾的, 既有抑制现象也有刺激现象 ${ }^{[15,60]}$. 而对于好氧 甲烷氧化菌代谢过程, MMO 会受 $\mathrm{Cu}$ 可用性的限制, 同时代谢过程中的酶也会受到环境的影响 ${ }^{[61-62]}$. 对于菌 种本身来说, 溶解性有机碳 (DOC) 浓度过高会导致好氧甲烷氧化菌丰度更高, 且可能会出现更高的 Type II 型好氧甲烷氧化菌比例 ${ }^{[63]}$. Ho 等 ${ }^{[6]}$ 表明, 无论组成群落的好氧甲烷氧化菌具体情况如何, 一个多样化好氧 甲烷氧化菌群落对于刺激 $\mathrm{CH}_{4}$ 氧化都具有重要意义.

\section{3 内陆水体好氧甲烷氧化速率数据分析}

\section{1 同位素测试甲烷氧化速率方法}

好氧甲烷氧化菌对不同重量碳元素的 $\mathrm{CH}_{4}$ 分子利用程度不同, 所以出现了在氧化一部分 $\mathrm{CH}_{4}$ 分子后, 剩 余的 $\mathrm{CH}_{4}$ 分子中 ${ }^{13} \mathrm{CH}_{4}$ 相对富集的情况 ${ }^{[65]}$, 这样的过程叫做同位素分馏. 同位素在动力学上的差异使我们可 以利用 $\mathrm{CH}_{4}$ 在氧化前后 $\delta^{13} \mathrm{C}$ 比值的差异来定量地表示 $\mathrm{CH}_{4}$ 氧化的速率.

在前期探索中, 许多研究者发现 $\mathrm{CH}_{4}$ 的氧化符合 Rayleigh 蒸馏公式 ${ }^{[65]}$, Coleman 等 ${ }^{[66]}$ 在 1981 年发表的 文章中推导并定义了一套 $\mathrm{CH}_{4}$ 氧化公式, 该公式与 Rayleigh 公式本质上相同, 都是对分馏系数 $\alpha$ 的探讨, 后 续在研究 $\mathrm{CH}_{4}$ 氧化速率中使用的分馏系数 $\alpha$ 含义也来源于此. 之后在 2002 年 Bastviken 等 ${ }^{[5]}$ 比较了当时主 流的几种 $\mathrm{CH}_{4}$ 氧化测试方法, 发现 ${ }^{14} \mathrm{C} 、{ }^{13} \mathrm{C}$ 和质量平衡模型都能展示相同的规律, 之后很多文献 ${ }^{[6-8]}$ 使用 ${ }^{13} \mathrm{C}$ 法来测量 $\mathrm{CH}_{4}$ 氧化速率的公式大多是基于此, 本文章的文献调查采用的好氧甲烷氧化速率也是基于此. 但 是在自然界, 并不是所有的地区都存在一个较高且合适的 $\mathrm{CH}_{4}$ 浓度, 同时也不能忽视好氧水体自生产 $\mathrm{CH}_{4}$ 现 象 ${ }^{[67]}$. 传统的测试方法在测量更低 $\mathrm{CH}_{4}$ 浓度条件下的氧化速率时就无法得到精确的数据, 并且在水体自身 产生 $\mathrm{CH}_{4}$ 的情况下会低估氧化速率. 而采用放射性同位素 ${ }^{3} \mathrm{H}$ 标记的 $\mathrm{CH}_{4}$ 分子可以在 $\mathrm{CH}_{4}$ 浓度非常低的情况 
下测得 $\mathrm{CH}_{4}$ 氧化速率. 但在实际操作中, 放射性同位素 ${ }^{3} \mathrm{H}$ 受本身造价以及更严格的控制条件要求并未大范 围运用在内陆水体中,而主要利于海水的 $\mathrm{CH}_{4}$ 氧化测试.

\section{2 全球内陆水体好氧甲烷氧化速率调查统计}

本文调查收集了好氧甲烷氧化速率 (methane oxidation rate, MOX) 研究全球范围内数据共 40 余篇文献, 文献均来自于 Web of Science 中公开发表的文献, 搜索关键词为 Methane oxidation、Aerobic methane oxidation、 Aerobic methane-oxidizing bacteria、Methane oxidation rate. 对检索到的文献进行分类, 删除海洋、河流人海口、 土壤研究. 文献调查含 39 个湖泊、 1 个河流、 2 个水库. 此外, 为方便比较, 文献检索中增加了 7 个河口与海 岸案例(图2).

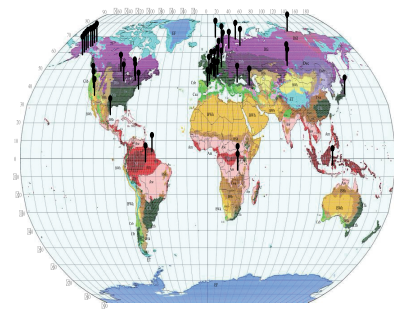

(A)

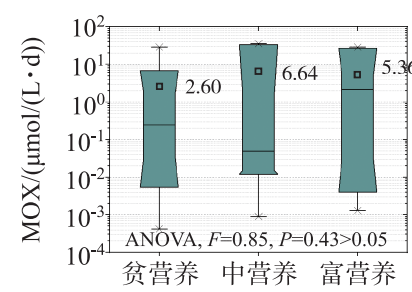

(D)

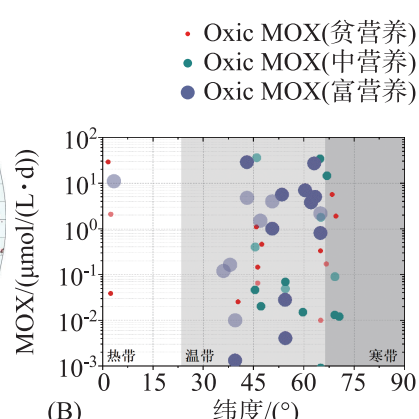

(B)

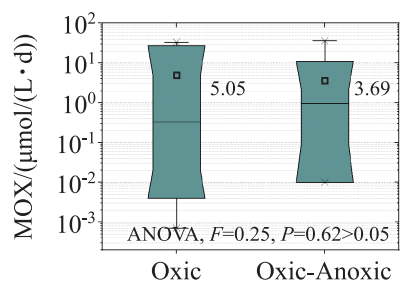

(E)
- Oxic-Anoxic MOX(贫营养)

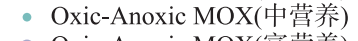

- Oxic-Anoxic MOX(富营养)

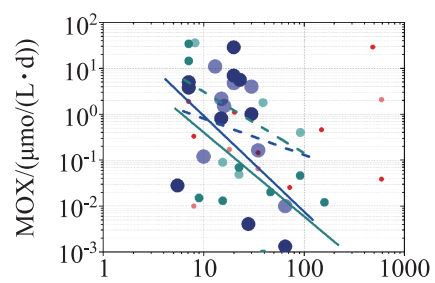

(C)

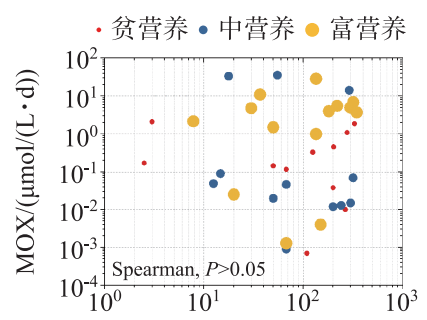

(F)

图 2 全球内陆水体好氧甲烷氧化速率分析

Fig.2 Analysis of aerobic methane oxidation rate in inland waters around the world

图 2 中, $\mathrm{A}$ 为相关检索案例在全球的分布情况, 本图在 Kottek 等 ${ }^{[68]}$ 的柯本气候图底图上修改; 图 2B 为 不同纬度水体中 MOX 分布; C 为不同水深 MOX 分布; Oxic MOX 代表在好氧环境下 MOX ( DO>2 mg/L); Oxic-Anoxic 表示水体中好氧一缺氧界面的 $\operatorname{MOX}(\mathrm{DO}=2 \mathrm{mg} / \mathrm{L}$ 临界值); 图 $2 \mathrm{C}$ 中直线代表水深与 Oxic MOX 线性拟合结果 $(P<0.05)$, 虚线代表水深与 Oxic-Anoxic MOX 线性拟合结果 $(P<0.05)$; 图 $2 \mathrm{D}$ 为不同营养状态 下 MOX 的统计, 包含了 Oxic 和 Oxic-Anoxic 两种情况; 图 2E 为好氧环境 (Oxic)、好氧一缺氧界面间 (OxicAnoxic) 的 MOX 统计; 图 $2 \mathrm{~F}$ 为不同营养状态水体 DO 浓度与 MOX 的关系. 为方便作图表达, 删除了若干个 极端数据值 (洪水爆发期、河流人海口海水倒灌等多种使水体短时间发生剧烈变化的情况).

MOX 测定的研究案例, 大部分集中在北纬 $30^{\circ} \sim 75^{\circ}$ 的温带和寒带地区 (图 2B), 且主要位于北美与欧洲 (图 2A). 湖泊是开展内陆水体好氧甲烷氧化研究的主要对象. 但大体上, 纬度差异并未影响不同内陆水体 的 MOX. 例如, 位于北纬 $45^{\circ}$ 加拿大的 Morency 湖泊 ${ }^{[69]}$ 和北纬 $71^{\circ}$ 俄罗斯的 Lena 河流 ${ }^{[70]}$ 对比研究发现, Lena 河外来输人有机质浓度较低且本身底物产 $\mathrm{CH}_{4}$ 能力较低, $\mathrm{MOX}$ 为 $\left.0.000419 \mu \mathrm{mol} / \mathrm{L} \cdot \mathrm{d}\right)$, 比 Morency 湖泊少 4 个数量级; 北纬 $65^{\circ} \mathrm{N}$, 属寒带气候的俄罗斯 Svetloe 湖 MOX 为 $0.0009 \mu \mathrm{mol} /(\mathrm{L} \cdot \mathrm{d})^{[71]}$ 比北纬 $46^{\circ}$ 属温带气 候的美国俄勒冈州 Spirit 湖 ${ }^{[72]}$ MOX 小 3 个数量级. 虽然 Svetloe 湖营养物质更丰富, 即便如此, 排除掉少数 数量级相差过大水体, 对主要数量级上的 MOX 做线性回归依然发现纬度对 MOX 无显著性相关. 营养状态、 DO 浓度变化亦未显著影响 MOX 变化 (图 2E、F), 但在中一富营养水体中 MOX 均值略高于贫营养水体 (图 2D). 富营养化的湖泊高光合速率、有机物生产力使得产 $\mathrm{CH}_{4}$ 底物浓度上升, 而缺乏营养物质输人的贫营养 
湖过低 $\mathrm{CH}_{4}$ 浓度限制着水体的 $\mathrm{CH}_{4}$ 氧化 ${ }^{[57,73]}$. 在不同水深 MOX 分布中 (图 $2 \mathrm{C}$ ), 发现贫营养水体 MOX 与水 深无显著相关 $(P>0.05)$, 而中一富营养水体 MOX 与水深显著负相关 (Spearman, $P<0.05)$, 其原因可能是 $\mathrm{CH}_{4}$ 由底部产生直至上覆水过程中, 由于水体过深导致气体在水柱中停留时间过长的综合作用下整个水柱 $\mathrm{CH}_{4}$ 氧化发生明显改变 ${ }^{[74]}$.

\section{4 不同类型内陆水体好氧甲烷氧化过程研究进展}

不同类型水体具有明显差异的水文条件、水环境条件与水生态特征, 所处地理区域及所受人类社会活 动影响大小的不同, 故本小节将对不同类型内陆水体 (湖泊、河流、水库为主) 以及其他内陆水环境好氧甲烷 氧化过程进行综述, 以期对不同内陆水体好氧甲烷氧化变化情况有更加明晰的把握.

\section{1 湖泊中的好氧甲烷氧化过程}

$\mathrm{CH}_{4}$ 的产生与氧化问题已在湖泊中进行了广泛研究, $\mathrm{CH}_{4}$ 是湖泊中碳代谢的主要产物, 在湖泊中产生的 $\mathrm{CH}_{4}$ 被氧化的比例可能很大 $(30 \% \sim 90 \%)$. 垂向分层通常是深水湖泊的一个属性, 溶解物质的积累导致上、 下层间的密度差异阻止了其完全混合, 相应的 DO 分层情况也十分明显 ${ }^{[75]}$; 而在一些存在湖面倾覆现象的 湖泊, 湖水因为水体混合导致深层储存的 $\mathrm{CH}_{4}$ 向湖面移动, 也会因为 $\mathrm{CH}_{4}$ 富集引发好氧甲烷氧化菌的大量繁 殖与生态演替同步对过量释放的 $\mathrm{CH}_{4}$ 进行消耗 ${ }^{[76]}$. 好氧甲烷氧化过程是一种需氧过程, 准确的说在通常情 况下是一种微需氧过程. $\mathrm{CH}_{4}$ 氧化受到 DO 浓度的限制 ${ }^{[77]}$. 在深层厌氧的大型湖泊中本身的 MOX 大小往往 取决于 $\mathrm{CH}_{4}$ 氧化层 (好氧甲烷氧化菌聚集并进行代谢的微氧区域) 的深度, $\mathrm{CH}_{4}$ 氧化层区域越广, MOX 就越 高, 这种氧化层的差异在季节性分层中尤为明显 ${ }^{[78]}$. 而与深水湖相比, 浅水湖水分层不易出现, 很多水体全 年水柱都是有氧状态 ${ }^{[79]}$, 这也使得可能经过计算后水体无明显的好氧甲烷氧化过程, 导致部分浅水湖对好 氧甲烷氧化菌研究需要延展到沉积物中.

虽然 DO 是好氧甲烷氧化过程所必需的物质, 但过高浓度会影响好氧甲烷氧化菌的活性从而降低

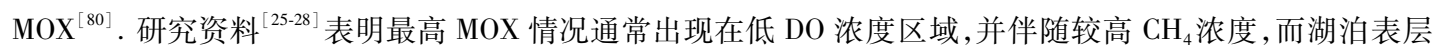
DO 浓度过高 MOX 显得会极为微小甚至无法检测. 有研究者 ${ }^{[80-81]}$ 发现低 DO 浓度与高有机物沉积速率相结 合, 会导致 “新鲜” 有机物更好地埋藏在沉积物中, 有利于 $\mathrm{CH}_{4}$ 生成. 同时湖泊水体的水柱缺氧时的水柱分层 阻碍了底部水和地表水之间的交换, 这又会进一步促进底部水中 $\mathrm{CH}_{4}$ 的积累. 然而湖泊中微氧并不总是能 观察到最高 $\mathrm{CH}_{4}$ 浓度, 其原因可能是过高 $\mathrm{MOX}$ 导致 $\mathrm{CH}_{4}$ 净产出量减少, 这也解释了为什么可能在深水湖泊 出现 MOX 大于 $\mathrm{CH}_{4}$ 产生速率的情况.

对低纬度热带湖泊、温带湖泊和北方湖泊进行比较, 与大多数生物代谢过程一样, $\mathrm{CH}_{4}$ 氧化也会表现出 温度依赖特点 ${ }^{[25]}$, 一年四季的高水温可能会使好氧甲烷氧化菌有着更高的活性, 因此常常能观察到低纬度 热带湖泊 MOX 大于后者 ${ }^{[78,82]}$, 且通常较高温度下可以观察到水体有着较快的 MOX 周转率 ${ }^{[52]}$. 而高纬度湖 泊占地球上所有湖泊的很大一部分,一年中的很多个月都可能被冰覆盖, 冰融化时期 $\mathrm{CH}_{4}$ 排放占全年 $\mathrm{CH}_{4}$ 排 放的比例较大, 高 MOX 也会出现在此阶段 ${ }^{[77]}$. 这主要是因为冻土中 DOC 大量输人所带来的营养物质能够 提高水体 $\mathrm{CH}_{4}$ 浓度 ${ }^{[74]}$. 例如 yedoma 类型冻土 (主要出现在西伯利亚、阿拉斯加和加拿大西北部以前未冰化 地区一种富含有机物的冻土) 由于温度升高冻土融化会带来大量的产 $\mathrm{CH}_{4}$ 底物 ${ }^{[77]}$.

内陆湖泊中 Type I 型好氧甲烷氧化菌主导着整个湖泊和水柱层的 $\mathrm{CH}_{4}$ 氧化活动, 对 $\mathrm{CH}_{4}$ 循环有着更显 著的作用, 例如 Washington、Constance 湖以及其他湖泊 ${ }^{[30,43,83]}$, 同时也发现 Type I 型好氧甲烷氧化菌通常 是温带湖泊中上层细菌群落的重要组成部分 ${ }^{[24]}$, 对于逃逸到水体中上层的 $\mathrm{CH}_{4}$ 起主要的消耗作用. 对部分 湖泊中上层水样进行功能基因测序, 发现 Type I 型好氧甲烷氧化菌中的 Methylobacter 属占主导地 位 ${ }^{[45,84-85]}$, 而在 Rotsee 湖和 Zug 湖中, 利用稳定同位素标记与单细胞成像质谱联用, 发现 Type I 型甲烷氧化 菌中的 Crenothrix polyspora 参与了氧跃层以下的 $\mathrm{CH}_{4}$ 氧化过程 ${ }^{86]}$. 一些低纬度热带湖泊中虽然表层的好氧 甲烷氧化菌是以 Type II 型为主, 但在营养程度更高的深层水体与底部沉积物依然是好氧甲烷氧化菌更为富 集 ${ }^{[87]}$. 而在湖泊沉积物中 Methylomonas、Methylosinus、Methylocystis 等多种 Type I 型好氧甲烷氧化菌是 $\mathrm{CH}_{4}$ 氧化过程的主要贡献者 ${ }^{[30,83,88]}$. 


\section{2 河流中的好氧甲烷氧化过程}

河流水文水动力条件明显不同于其他内陆水体, 且受人类社会活动影响较大. 相对于大气,许多河流表 层的 $\mathrm{CH}_{4}$ 和 $\mathrm{CO}_{2}$ 都过饱和, 河流也因此成为了快速的碳循环场所. 虽然一部分碳最终被输人到海洋, 但更多 的碳在河流中代谢并以 $\mathrm{CH}_{4}$ 气体的形式流失到大气中 ${ }^{[89]}$, 由于这种快速的异源输人, 河流向大气排放 $\mathrm{CH}_{4}$ 的潜力在不断接受社会影响下对大气中的温室气体影响日益加重. 河流砾石河床会对 $\mathrm{CH}_{4}$ 生产做出快速的 响应, 即 $\mathrm{CH}_{4}$ 的氧化, 从而减轻 $\mathrm{CH}_{4}$ 通过沉积物层的扩散 (清水河流水柱 $\mathrm{CH}_{4}$ 氧化层一般可以忽略不计), 所 以一旦 $\mathrm{CH}_{4}$ 处于河流沉积物中上层, 可渗透的有氧砾石河床便成为减少 $\mathrm{CH}_{4}$ 扩散排放的最终屏障. 而由于不 同河流水体之间的水力条件差异较大且水体本身周转周期较快, 同时河流一般无法像水库以及湖泊出现特 别明显的水分层现象,微氧区域很难出现在河流水体中.

在所有水层中, 表层水体接受的光辐射强度最大, 河流由于其水深较浅受到光照影响也就最为明显. 光 辐射强度过大会抑制好氧甲烷氧化菌的活性 ${ }^{[28]}$, 使得在昼夜循环中 MOX 表现出较大的差异. 同时由于水 体光辐射强度会受到 DOC 浓度的影响而加快衰减, 因而上部光照充足的水层中 DOC 浓度是光照对 MOX 影 响的重要预测因子, 但是在光线抑制不再是有效驱动因素的黑暗深层水中会被 DO 浓度所取代 ${ }^{[25]}$. 河流沿 程光照条件复杂、微氧区域分散、DOC 输人来源众多 (很多河流靠近人类生活生产), 所以单条河流好氧甲烷 氧化菌生境的研究对整个河流生态体系代表性意义并不大, 更多对河流的研究都集中在了 MOX 与其影响 因素上.

$\mathrm{CH}_{4}$ 作为好氧甲烷氧化菌主要的碳源能量, $\mathrm{MOX}$ 与 $\mathrm{CH}_{4}$ 生产率是相辅相成的, 且 $\mathrm{MOX}$ 对 $\mathrm{CH}_{4}$ 浓度变化 响应最为敏感 ${ }^{[27,69]}$. 当河流中的 DO 浓度满足好氧甲烷氧化菌需求, $\mathrm{CH}_{4}$ 浓度对 MOX 的影响明显高于 DO 浓度. 与在许多湖泊和土壤中一样, $\mathrm{CH}_{4}$ 异养作用在河床沉积物中也受底物限制, 因此 MOX 随 $\mathrm{CH}_{4}$ 浓度的增 加基本呈线性增加 ${ }^{[8]}$. 中小型河流中, 河床砾石级配对 MOX 有一定影响. Shelley 等 ${ }^{[8]}$ 发现粗砂砾河床 MOX 因 $\mathrm{CH}_{4}$ 底物浓度较低而受限; 在较细的泥沙淤积区域 MOX 显著升高( 细颗粒沉积物由于其密集的形态拥有 更大的 $\mathrm{CH}_{4}$ 容量, 会同时生成 $\mathrm{CH}_{4}$ 和氧化 $\mathrm{CH}_{4}$ ), 受温度影响显著, 并超过 $\mathrm{CH}_{4}$ 产生速率. 若河流受光条件不 佳甚至受到遮挡, 河流 MOX 则显著升高约 $78 \%{ }^{[90]}$; 而在 Elbe 河的研究发现, 好氧甲烷氧化过程主要存在于 河床, MOX 在上游山区河段明显强于下游低地河段 ${ }^{[91-92]}$. Barbosa 等 ${ }^{[82]}$ 对河流的季节性研究则发现, 河流由 于季节性枯水与丰水在水位和流量上有很大波动, 使 MOX 有显著改变. 而其中部分河流季节性丰水期会发 现夏、秋季 $\mathrm{CH}_{4}$ 总损失量会高于春、冬季 ${ }^{[52,82]}$, 且季节性降雨所导致的水温变化可直接影响微生物代谢率, 例如产甲烷菌和甲烷氧化菌. 而由于咸水中存在的物理、化学机理, 河流人海口处的盐度和悬浮颗粒物浓度 能强烈影响 MOX, 有研究表明水体中盐度能对 MOX 产生一定抑制作用, 而悬浮颗粒物浓度对 MOX 表现为 积极影响 ${ }^{[52]}$.

\section{3 水库中的好氧甲烷氧化过程}

水库是受人为影响下的大型内陆水体, 由于其产 $\mathrm{CH}_{4}$ 底物与 $\mathrm{CH}_{4}$ 的来源丰富, $\mathrm{CH}_{4}$ 的生产、运输、氧化过 程更为复杂. 水库 $\mathrm{CH}_{4}$ 主要排放途径分为三类: 浅水区气泡释放、水一气界面扩散释放、水轮机和溢洪道下游 的消气释放. 与湖泊相同, 由于热带地区水库水温较高, 有利于有机物的降解, $\mathrm{CH}_{4}$ 生产和氧化高于相似条件 下的温带、北方水库, 同时 MOX 也相应很高 ${ }^{[27,93]}$. 水库由于其调蓄作用导致其水力条件季节性变化明显, 而 季节变化带来的温度变化有时会严重影响 $\mathrm{CH}_{4}$ 在亚热带和热带水库的深层区域中的生产, 使得 $\mathrm{CH}_{4}$ 氧化受 $\mathrm{CH}_{4}$ 浓度限制 ${ }^{[94]}$. 同时在春季和夏季, 有的水库强分层, DO 渗透并不够, 好氧甲烷氧化菌只能在更小的范围 内活动 ${ }^{[93]}$. 这与 Lofton 等 $^{[95]}$ 提出的特定基质一温度相互作用理论相吻合, 只有 $\mathrm{CH}_{4}$ 处于饱和条件下 MOX 受 到温度的影响能明显观察到, 即在限制 $\mathrm{CH}_{4}$ 浓度时温度对 MOX 影响并不明显, 因此 MOX 还依赖于一套与 温度相互关联的其他环境变量, 这在温度分层和氧分层尤为明显的深水水库十分重要. 同时温度对底层水 中 $\mathrm{CH}_{4}$ 氧化的影响可能受到水中 $\mathrm{DO}$ 浓度的调节, 而在低氧条件下, 温度变化没有明显影响 $\mathrm{CH}_{4}$ 氧化 ${ }^{[25]}$. 且 由于水库的水分层现象, 在不同水层运输过程中 $\mathrm{CH}_{4}$ 向上扩散和 DO 向下渗透都会受到一定的影响 ${ }^{[96]}$. 因 此在水库水分层与混合不同阶段会发现 $\mathrm{CH}_{4}$ 浓度和 $\mathrm{DO}$ 浓度有相当大的差异, 好氧甲烷氧化菌生长区域也 会因此受限. Type I 型甲烷氧化菌和 Type II 型好氧甲烷氧化菌在水库中因 DO 构成的氧化层中均有广泛 的分布. 在亚热带水库 (Little Nerang Dam、Lake Baroon 和 Lake Wivenhoe) 可以发现丰富 Type I 型好氧甲烷 
氧化菌（如 Crenothrix polyspora、Methylomonas、Methylocaldum) ${ }^{[93]}$. 而位于法属圭亚那的 Petit-Saut Reservoir 则 观察到了 Type II 型好氧甲烷氧化菌占据着主要的 $\mathrm{CH}_{4}$ 氧化活动 ${ }^{[27]}$.

水库拥有着特殊水利条件与消落带涨落情况, 这使得水库有着高外来输人有机碳的特点. 低中营养内 陆水体中陆地来源的 DOC 会明显影响水体的颜色, 水体颜色变化比温跃层深度更能减少光的穿透, 达到光 抑制作用 ${ }^{[97]}$, 使得表层光照强度下降从而提高表层 MOX, 并由于表层水 DO 的更多消耗进一步导致缺氧性 水层扩展到了较浅的深度, 形成深层水体缺氧状态. 因此控制水库等内陆水体的 $\mathrm{CH}_{4}$ 氧化有 2 个尤为重要 的变量一DO 浓度和有效光辐射, 这两者会受到水体中 DOC 浓度的影响, 从而使得 DOC 浓度间接影响 MOX. 同时, 水库底部的有机物本身矿化过程所导致的耗氧也会影响 $\mathrm{CH}_{4}$ 通过好氧甲烷氧化菌被氧化. 而对 于菌种本身来说, DOC 浓度过高通常会伴随着更高的好氧甲烷氧化菌丰度, 且可能会出现更高的 Type II 型 好氧甲烷氧化菌比例 ${ }^{[63]}$.

\section{4 其他内陆水环境的好氧甲烷氧化过程}

湿地生态系统是陆地自然生态系统与水体自然生态系统的特殊过渡型生态系统. 湿地生态系统占内陆 面积不超过 $10 \%$, 含碳量占内陆总储存碳量的 $18 \%{ }^{[98]}$, 但向大气释放 $\mathrm{CH}_{4}$ 总量却占据了全球自然生态系统 的 $\mathrm{CH}_{4}$ 排放总量的 $30 \%$ 左右 ${ }^{[99]}$. 好氧甲烷氧化菌在湿地生态系统中约能氧化掉其 $\mathrm{CH}_{4}$ 产量的一半左右, 但 无法像内陆水体一样提供更为广的好氧甲烷氧化菌生存区域而导致部分湿地其 $\mathrm{CH}_{4}$ 氧化可能是由厌氧微 生物介导, 同时湿地水文条件也决定了湿地生态系统有着较高的 $\mathrm{CH}_{4}$ 逃逸率, 使其成为了自然生态系统主 要的排放源之一 ${ }^{[82]}$. 目前湿地发现的好氧甲烷氧化菌主要为 $\alpha$-变形菌和 $\gamma$-变形杆菌, 并未发现 Verrucomicrobia 门. 其中属于 Type II 型好氧甲烷氧化菌最先由 McDonald 团队发现, 同时揭示了偏酸性湿地的主要菌 种来源是 Methylosinus 和 Methylocystis, 后者发现在偏酸性湿地处于更加常见的位置 ${ }^{[100-102]}$. 而后 Type I 型好 氧甲烷氧化菌也在一些自然湿地被逐步发现 ${ }^{[103]}$, 其中 Kip 等 ${ }^{[104]}$ 首次发现了适应酸性湿地环境的 Type I 型好氧甲烷氧化菌. 在大量的湿地研究中 Methylocystis 通常占据着主要的 $\mathrm{CH}_{4}$ 氧化工作, 在偏酸性湿地基本 也是 Type II 型好氧甲烷氧化菌; 而在极端寒冷条件下的湿地生态系统中 Type I 型好氧甲烷氧化菌占比更 大. 相应的,我国对于若尔盖湿地、日干乔湿地等地区近些年也开启了相应的研究,发现 Type I 型好氧甲烷 氧化菌占比更大, 且 Methylobacter、Methylocystis 两类菌种是主要的 $\mathrm{CH}_{4}$ 氧化参与者 ${ }^{[17,105]}$.

浅水池塘作为内陆水体的一部分其碳动态关注度也在逐渐升高 ${ }^{[106]}$. 这类小型浅层水系统其系统特征 会影响 $\mathrm{CH}_{4}$ 排放以及氧化, 并能从一定程度上解释部分地区 $\mathrm{CH}_{4}$ 排放被低估的现象有可能来自于浅水池 塘 ${ }^{[07]}$. 例如, 在人为活动影响下的水产养殖池是强温室气体 $\mathrm{CH}_{4}$ 排放源, 通常其气泡形态排放的 $\mathrm{CH}_{4}$ 占比 会明显高于其他水体 ${ }^{[108-109]}$. 而其他内陆环境, 例如森林、草原甚至垃圾填埋场也会发现好氧甲烷氧化菌的 身影, 但由于其不容易满足好氧甲烷氧化菌生存与代谢环境使得好氧甲烷氧化菌无法大量氧化 $\mathrm{CH}_{4}$ 的产出.

\section{5 内陆水体好氧甲烷氧化过程对全球碳循环的贡献}

内陆水体作为全球 $\mathrm{CH}_{4}$ 预算的重要来源, 自然生态中考虑到开放水域和植物介导的通量, 湖泊生态系 统被认为对总的自然 $\mathrm{CH}_{4}$ 排放有 $6 \% \sim 16 \%$ 的贡献 ${ }^{[110]}$. 河流向大气释放 $\mathrm{CH}_{4}$ 年均总量约为 $26.8 \mathrm{Tg} / \mathrm{a}$; 水库 向大气释放 $\mathrm{CH}_{4}$ 年均总量约为 $17.7 \mathrm{Tg} / \mathrm{a}^{[4,111]}$, 两者分别占全球内陆水体向大气释放 $\mathrm{CH}_{4}$ 总量的 $16 \% 、 22 \%$. 内陆水体对大气温室气体的贡献是 $\mathrm{CH}_{4}$ 在水环境中 “源”与 “汇” 动态平衡下的结果, 也就是产甲烷菌产出与 甲烷氧化菌氧化共同调节下的整体反馈. 实际上来自于水体产生的 $\mathrm{CH}_{4}$ 总量远大于监测到输人大气的 $\mathrm{CH}_{4}$ 总量. 但由于两类菌在温室效应下温度抬升的响应不同,这种“源”与 “汇”的动态平衡始终以“源”大于“汇” 的正向反馈为主, 形成了全球变暖正反馈回路机制 ${ }^{[112]}$. 即温度抬升刺激 “源” 大于 “汇” 的动态平衡导致 $\mathrm{CH}_{4}$ 排放进一步增加继续扩大全球变暖, 这样 $\mathrm{CH}_{4}$ 反馈回路也同步反映在了全球碳循环的反馈回路中. 在最 近的研究中, 通过将甲烷氧化菌对 $\mathrm{CH}_{4}$ 的敏感程度进行划分, 所展现出的 $\mathrm{CH}_{4}$ 高敏性甲烷氧化菌对全球碳循 环的 $\mathrm{CH}_{4}$ “汇” 有着更为明显作用, 使得好氧甲烷氧化过程对全球碳循环的贡献日渐明晰 ${ }^{[113]}$. 而随着研究者 不断对极端生境下新类型甲烷氧化菌以及更多兼性甲烷氧化菌的发现, 也对全球碳收支运算提出了更高更 精细的要求,推动着人类对 $\mathrm{CH}_{4}$ 循环、碳循环的进一步认知.

从菌种本身来看, 好氧甲烷氧化菌广泛的分布在内陆水体 (湖泊、河流、水库、浅水池塘)、湿地、森林、草 
原等陆地生态系统环境中. 菌群以碳源作为生产代谢的能源, 其介导的好氧甲烷氧化过程是全球碳循环重 要的微生物调节. 一方面, 好氧甲烷氧化过程理想情况下几乎可以氧化掉所有水体底部产生的 $\mathrm{CH}_{4}$, 是 $\mathrm{CH}_{4}$ 由水体向大气释放过程中的“生物过滤器” 和 “最后屏障” [114-116]. 另一方面, 好氧甲烷氧化过程使 $\mathrm{CH}_{4}$ 成为 水生生态系统中重要的碳源 ${ }^{[117]}$. 它直接促进了好氧甲烷氧化菌的增殖, 并逐渐丰富形成了以 “好氧甲烷氧 化菌一浮游或底栖动物” 为核心的微食物环 ${ }^{[118-119]}$, 对水生生态系统结构功能产生显著影响 ${ }^{[120]}$.

\section{6 展望}

尽管目前对不同类型好氧甲烷氧化菌的生境偏好已有基本轮廓, 但对于动态水文环境如何影响好氧甲 烷氧化菌菌群建构与生态功能迄今仍鲜有报道, 这成为了当前动态水文环境下好氧甲烷氧化过程水文生态 机制仍不明晰的关键制约因素, 特别是突发的极端因素变化 (如气温骤变、强降雨、季节性干旱、洪涝等), 从 而导致好氧甲烷氧化菌的生存条件改变, 需要更多细致的研究. 且在当前内陆水体好氧甲烷过程研究中, 超 过 $90 \%$ 的研究案例集中于水文环境相对稳定的湖泊或湿地系统,而在流动性较强或水动力条件较为复杂的 水体中, 好氧甲烷氧化过程的研究积累却极为有限. 这一块重要的内陆水体组成部分数据上的空白, 是今后 研究内陆水体好氧甲烷氧化过程需要补充的重要内容.

\section{7 参考文献}

[ 1 ] Wuebbles DJ, Hayhoe K. Atmospheric methane and global change. Earth-Science Reviews, 2002, 57 (3/4) : 177-210. DOI: $10.1016 /$ S0012-8252(01)00062-9.

[ 2 ] Dlugokencky E. NOAA/ESRL. US, 2019.

[ 3 ] Bastviken D, Tranvik LJ, Downing JA et al. Freshwater methane emissions offset the continental carbon sink. Science, 2011, 331(6013) : 50. DOI: 10.1126/science.1196808.

[ 4 ] Stanley EH, Casson NJ, Christel ST et al. The ecology of methane in streams and rivers: patterns, controls, and global significance. Ecological Monographs, 2016, 86(2) : 146-171. DOI: 10.1890/15-1027.

[ 5 ] Bastviken D, Ejlertsson J, Tranvik L. Measurement of methane oxidation in lakes: A comparison of methods. Environmental Science \& Technology, 2002, 36(15) : 3354-3361. DOI: 10.1021/es010311p.

[ 6 ] Thottathil SD, Reis PCJ, Del Giorgio PA et al. The extent and regulation of summer methane oxidation in northern lakes. Journal of Geophysical Research: Biogeosciences, 2018, 123(10) : 3216-3230. DOI: 10.1029/2018JG004464

[ 7 ] Saarela T, Rissanen AJ, Ojala A et al. $\mathrm{CH}_{4}$ oxidation in a boreal lake during the development of hypolimnetic hypoxia. Aquatic Sciences, 2020, 82(2). DOI: 10.1007/s00027-019-0690-8.

[ 8 ] Shelley F, Abdullahi F, Grey J et al. Microbial methane cycling in the bed of a chalk river: oxidation has the potential to match methanogenesis enhanced by warming. Freshwater Biology, 2015, 60(1) : 150-160. DOI: 10.1111/fwb.12480.

[ 9 ] Crevecoeur S, Ruiz-González C, Prairie YT et al. Large-scale biogeography and environmental regulation of methanotrophic bacteria across boreal inland waters. Molecular Ecology, 2019, 28(18) : 4181-4196. DOI: 10.1111/mec.15223.

[10] Semrau JD, Dispirito AA, Gu WY et al. Metals and methanotrophy. Applied and Environmental Microbiology, 2018,84 (6). DOI: 10.1128/AEM.02289-17.

[11] Chan SI, Yu SSF. Copper protein constructs for methane oxidation. Nature Catalysis, 2019, 2(4) : 286-287. DOI: 10. 1038/s41929-019-0268-9.

[12] Guggenheim C, Brand A, Bürgmann H et al. Aerobic methane oxidation under copper scarcity in a stratified lake. Scientific Reports, 2019, 9. DOI: 10.1038/s41598-019-40642-2.

[13] Hakemian AS, Rosenzweig AC. The biochemistry of methane oxidation. Annual Review of Biochemistry, 2007, 76: 223241. DOI: 10.1146/annurev.biochem.76.061505.175355.

[14] Hwang IY, Hur DH, Lee JH et al. Batch conversion of methane to methanol using Methylosinus trichosporium OB3b as biocatalyst. Journal of Microbiology and Biotechnology, 2015, 25(3) : 375-380. DOI: 10.4014/jmb.1412.12007.

[15] Hanson RS, Hanson TE. Methanotrophic bacteria. Microbiological Reviews, 1996, 60(2). DOI: 10.1128/MMBR.60.2. 439-471.1996.

[16] Bowman JP, Sly LI, Nichols PD et al. Revised taxonomy of the methanotrophs-description of methylobacter gen-nov, 
emendation of Methylococcus, validation of Methylosinus and Methylocystis species, and a proposal that the family methylococcaceae includes only the group-i methanotrophs. International Journal Systematic Bacteriology, 1994, 44(2) : 375-375. DOI: 10.1099/00207713-44-2-375.

[17] Deng YC, Cui XY, Luke C et al. Aerobic methanotroph diversity in Riganqiao peatlands on the Qinghai-Tibetan Plateau. Environmental Microbiology Reports, 2013, 5(4) : 566-574. DOI: 10.1111/1758-2229.12046.

[18] Dumont MG, Luke C, Deng YC et al. Classification of pmoA amplicon pyrosequences using BLAST and the lowest common ancestor method in MEGAN. Frontiers in Microbiology, 2014, 5. DOI: 10.3389/fmicb.2014.00034.

[19] Knief C. Diversity and habitat preferences of cultivated and uncultivated aerobic methanotrophic bacteria evaluated based on pmoA as molecular marker. Frontiers in Microbiology, 2015, 6. DOI: 10.3389/fmicb.2015.01346.

[20] Dunfield PF, Yuryev A, Senin P et al. Methane oxidation by an extremely acidophilic bacterium of the phylum Verrucomicrobia. Nature, 2007, 450(7171). DOI: 10.1038/nature06411.

[21] Van Teeseling MCF, Pol A, Harhangi HR et al. Expanding the verrucomicrobial methanotrophic world: Description of three novel species of Methylacidimicrobium gen. nov. Applied Environmental Microbiology, 2014, 80(21): 6782-6791. DOI: 10.1128 /AEM.01838-14.

[22] Pol A, Heijmans K, Harhangi HR et al. Methanotrophy below pH 1 by a new Verrucomicrobia species. Nature, 2007, 450 (7171) : 874-917. DOI: 10.1038/nature06222.

[23] Deng YC, Che RX, Wu YB et al. A review of the physiological and ecological characteristics of methanotrophs and methanotrophic community diversity in the natural wetlands. Acta Ecologica Sinica, 2015, 35(14) : 4579-4591. DOI: 10.10. 5846/stxb201305060936. [邓永翠, 车荣晓, 吴伊波等. 好氧甲烷氧化菌生理生态特征及其在自然湿地中的群落多 样性研究进展. 生态学报, 2015, 35(14): 4579-4591.]

[24] Sundh I, Bastviken D, Tranvik LJ. Abundance, activity, and community structure of pelagic methane-oxidizing bacteria in temperate lakes. Applied and Environmental Microbiology, 2005, 71(11) : 6746-6752. DOI: 10.1128/AEM.71.11.67466752.2005 .

[25] Thottathil SD, Reis PCJ, Del Giorgio PA et al. The extent and regulation of summer methane oxidation in northern lakes. Journal of Geophysical Research-Biogeosciences, 2018, 123(10) : 3216-3230. DOI: 10.1029/2018JG004464.

[26] Lin JL, Joye SB, Scholten JCM et al. Analysis of methane monooxygenase genes in mono lake suggests that increased methane oxidation activity may correlate with a change in methanotroph community structure. Applied Environmental Microbiolo$g y, 2005,71(10)$ : 6458-6462. DOI: 10.1128/AEM.71.10.6458-6462.2005.

[27] Guerin F, Abril G. Significance of pelagic aerobic methane oxidation in the methane and carbon budget of a tropical reservoir. Journal of Geophysical Research-Biogeosciences, 2007, 112 (G3). DOI: 10.1029/2006JG000393.

[28] Oswald K, Milucka J, Brand A et al. Light-dependent aerobic methane oxidation reduces methane emissions from seasonally stratified lakes. Public Library of Science, 2015, 10(7). DOI: 10.1371/journal.pone.0132574.

[29] Deutzmann JS, Wörner S, Schink B. Activity and diversity of methanotrophic bacteria at methane seeps in eastern lake constance sediments. Applied and Environmental Microbiology, 2011, 77 (8) : 2573-2581. DOI: 10.1128/AEM.02776-10.

[30 ] Costello AM, Auman AJ, Macalady JL et al. Estimation of methanotroph abundance in a freshwater lake sediment. Environmental Microbiology, 2002, 4(8) : 443-450. DOI: 10.1046/j.1462-2920.2002.00318.x.

[31] Henckel T, Roslev P, Conrad R. Effects of $\mathrm{O}_{2}$ and $\mathrm{CH}_{4}$ on presence and activity of the indigenous methanotrophic community in rice field soil. Environmental Microbiology, 2000, 2(6) : 666-679. DOI: 10.1046/j.1462-2920.2000.00149.x.

[32] Ho A, Kerckhof FM, Luke C et al. Conceptualizing functional traits and ecological characteristics of methane-oxidizing bacteria as life strategies. Environmental Microbiology Reports, 2013, 5(3) : 335-345. DOI: 10.1111/j.1758-2229.2012. 00370.x.

[33] Shivaji S, Kumari K, Kishore KH et al. Vertical distribution of bacteria in a lake sediment from Antarctica by culture-independent and culture-dependent approaches. Research in Microbiology, 2011, 162(2) : 191-203. DOI: 10.1016 /j.resmic. 2010.09.020.

[34] Horz HP, Rich V, Avrahami S et al. Methane-oxidizing bacteria in a California upland grassland soil: Diversity and response to simulated global change. Applied and Environmental Microbiology, 2005, 71(5) : 2642-2652. DOI: 10.1128/ AEM.71.5.2642-2652.2005.

[35] Medvedkova KA, Khmelenina VN, Trotsenko YA. Sucrose as a factor of thermal adaptation of the thermophilic methanotro- 
ph Methylocaldum szegediense O-12. Microbiology, 2007, 76(4) : 500-502. DOI: 10.1134/S00262617 07040170.

[36] Trotsenko YA, Khmelenina VN. Aerobic methanotrophic bacteria of cold ecosystems. FEMS Microbiology Ecology, 2005, 53(1) : 15-26. DOI: 10.1016/j.femsec.2005.02.010.

[37] Urmann K, Lazzaro A, Gandolfi I et al. Response of methanotrophic activity and community structure to temperature changes in a diffusive $\mathrm{CH}_{4} / \mathrm{O}_{2}$ counter gradient in an unsaturated porous medium. FEMS Microbiology Ecology, 2009, 69(2) : 202-212. DOI: 10.1111/j.1574-6941.2009.00708.x.

[38] Mohanty SR, Bodelier PLE, Conrad R. Effect of temperature on composition of the methanotrophic community in rice field and forest soil. FEMS Microbiology Ecology, 2007, 62(1) : 24-31. DOI: 10.1111/j.1574-6941.2007.00370.x.

[39] Graef C, Hestnes AG, Svenning MM et al. The active methanotrophic community in a wetland from the High Arctic. Environmental Microbiology Reports, 2011, 3(4) : 466-472. DOI: 10.1111/j.1758-2229.2010.00237.x.

[40] Liebner S, Wagner D. Abundance, distribution and potential activity of methane oxidizing bacteria in permafrost soils from the Lena Delta, Siberia. Environmental Microbiology, 2007, 9(1) : 107-117. DOI: 10.1111/j.1462-2920.2006.01120.x.

[41] Tsubota J, Eshinimaev BT, Khmelenina VN et al. Methylothermus thermalis gen. nov., sp. nov., a novel moderately thermophilic obligate methanotroph from a hot spring in Japan. International Journal of Systematic and Evolutionary Microbiology, 2005, 55: 1877-1884. DOI: 10.1099/ijs.0.63691-0.

[42] Dedysh SN, Knief C, Dunfield PF. Methylocella species are facultatively methanotrophic. Journal of Bacteriology, 2005 , 187(13) : 4665-4670. DOI: 10.1128/JB.187.13.4665-4670.2005.

[43] Reis PCJ, Thottathil SD, Ruiz-GonzaLez C et al. Niche separation within aerobic methanotrophic bacteria across lakes and its link to methane oxidation rates. Environmental Microbiology, 2020, 22 ( 2 ) : 738-751. DOI: 10. 1111/14622920.14877.

[44] Rudd J, Hamilton R. Factors controlling rates of methane oxidation and distribution of methane oxidizers in a small stratified lake. Archiv fuir Hydrobiologie, 1975, 75(4) : 522-538.

[45] Biderre-Petit C, Jézéquel D, Dugat-Bony E et al. Identification of microbial communities involved in the methane cycle of a freshwater meromictic lake. FEMS Microbiology Ecology, 2011, 77 (3) : 533-545. DOI: 10.1111/j. 1574-6941.2011. 01134.x.

[46] Ren T, Amaral JA, Knowles R. The response of methane consumption by pure cultures of methanotrophic bacteria to oxygen. Canadian Journal of Microbiology, 1997, 43(10) : 925-928. DOI: 10.1139/m97-133.

[47] Kalyuzhnaya MG, Yang S, Rozova ON et al. Highly efficient methane biocatalysis revealed in a methanotrophic bacterium. Nature Communications, 2013, 4. DOI: 10.1038/ncomms3785.

[48] Rostkowski KH, Pfluger AR, Criddle CS. Stoichiometry and kinetics of the PHB-producing Type II methanotrophs Methylosinus trichosporium OB3b and Methylocystis parvus OBBP. Bioresource Technology, 2013, 132: 71-77. DOI: 10.1016/j. biortech.2012.12.129.

[49] Steinle L, Maltby J, Treude T et al. Effects of low oxygen concentrations on aerobic methane oxidation in seasonally hypoxic coastal waters. Biogeosciences, 2017, 14(6) : 1631-1645. DOI: 10.5194/bg-14-1631-2017.

[50] Kadnikov VV, Savvichev AS, Mardanov AV et al. Microbial communities involved in the methane cycle in the near-bottom water layer and sediments of the meromictic subarctic Lake Svetloe. Antonie van Leeuwenhoek International Journal of General and Molecular Microbiology, 2019, 112(12) : 1801-1814. DOI: 10.1007/s10482-019-01308-1.

[51] Milucka J, Kirf M, Lu L et al. Methane oxidation coupled to oxygenic photosynthesis in anoxic waters. The ISME journal, 2015, 9(9) : 1991-2002. DOI: 10.1038/ismej.2015.12.

[52] Matoušu A, Osudar R, Šimek K et al. Methane distribution and methane oxidation in the water column of the Elbe estuary, Germany. Aquatic Sciences, 2016, 79(3) : 443-458. DOI: 10.1007/s00027-016-0509-9.

[53] Lei D, Liu J, Zhang JW et al. Methane oxidation in the water column of xiangxi Bay, Three Gorges Reservoir. Clean-Soil Air Water, 2019, 47(9). DOI: 10.1002/clen.201800516.

[54] Lambrecht N, Katsev S, Wittkop C et al. Biogeochemical and physical controls on methane fluxes from two ferruginous meromictic lakes. Geobiology, 2020, 18(1) : 54-69. DOI: 10.1111/gbi.12365.

[55] Van Bodegom P, Stams F, Mollema L et al. Methane oxidation and the competition for oxygen in the rice rhizosphere. Applied and Environmental Microbiology, 2001, 67(8) : 3586-3597. DOI: 10.1128/AEM.67.8.3586-3597.2001.

[56] Horz HP, Raghubanshi AS, Heyer E et al. Activity and community structure of methane-oxidising bacteria in a wet mead- 
ow soil. FEMS Microbiology Ecology, 2002, 41(3) : 247-257. DOI: 10.1016/S0168-6496(02)00300-8.

[57] Denfeld BA, Ricão Canelhas M, Weyhenmeyer GA et al. Constraints on methane oxidation in ice-covered boreal lakes. Journal of Geophysical Research: Biogeosciences, 2016, 121(7) : 1924-1933. DOI: 10.1002/2016JG003382.

[58] Semrau JD, Dispirito AA, Yoon S. Methanotrophs and copper. FEMS Microbiology Reviews, 2010, 34(4): 496-531. DOI: $10.1111 /$ j.1574-6976.2010.00212.x.

[59] Zhu J, Wang Q, Yuan MD et al. Microbiology and potential applications of aerobic methane oxidation coupled to denitrification (AME-D) process: A review. Water Research, 2016, 90: 203-215. DOI: 10.1016/j.watres.2015.12.020.

[60] Bastviken D. Methane// Likens GE ed. Encyclopedia of inland waters. Oxford: Academic Press, 2009: 783-805.

[61] Semrau JD, Zolandz D, Lidstrom ME et al. The role of copper in the pmmo of Methylococcus capsulatus bath-a structural vs catalytic function. Journal of Inorganic Biochemistry, 1995, 58 ( 4 ) : 235-244. DOI: 10. 1016/0162-0134 ( 94 ) 00056-G.

[62] Ferenci T, Strom T, Quayle JR. Purification and properties of 3-hexulose phosphate synthase and phospho-3-hexuloisomerase fromMethylococcus-capsulatus. Biochemical Journal, 1974, 144(3) : 477-486. DOI: 10.1042/bj1440477.

[63] Yang YY, Chen JF, Tong TL et al. Eutrophication influences methanotrophic activity, abundance and community structure in freshwater lakes. Science of the Total Environment, 2019, 662: 863-872. DOI: 10.1016/j.scitotenv.2019.01.307.

[64] Ho A, De Roy K, Thas O et al. The more, the merrier: heterotroph richness stimulates methanotrophic activity. The ISME Journal, 2014, 8(9) : 1945-1948. DOI: 10.1038/ismej.2014.74.

[65] Whiticar MJ. Carbon and hydrogen isotope systematics of bacterial formation and oxidation of methane. Chemical Geology, 1999, 161 (1-3) : 291-314. DOI: 10.1016/S0009-2541(99)00092-3.

[66] Coleman DD, Risatti JB, Schoell M. Fractionation of carbon and hydrogen isotopes by methane-oxidizing bacteria. Geochimica et Cosmochimica Acta, 1981, 45(7) : 1033-1037. DOI: 10.1016/0016-7037(81)90129-0.

[67] Yang L. Research process on "methane paradox” phenomenon in lake surface waters. Chinese Journal of Ecology, 2020, 39 (14) : 1338-1348. DOI: 10.13292/j.1000-4890.202004.033. [杨乐. 湖泊表层水体“甲烷悖论” 现象研究进展. 生 态学杂志, $2020,39(14): 1338-1348$. ]

[68] Kottek M, Grieser J, Beck C et al. World map of the Köppen-Geiger climate classification updated. Meteorologische Zeitschrift, 2006, 15(3) : 259-263. DOI: 10.1127/0941-2948/2006/0130.

[69] Thottathil SD, Reis PCJ, Prairie YT. Methane oxidation kinetics in northern freshwater lakes. Biogeochemistry, 2019, 143 (1) : 105-116. DOI: 10.1007/s10533-019-00552-x.

[70] Bussmann I, Hackbusch S, Schaal P et al. Methane distribution and oxidation around the Lena Delta in summer 2013. Biogeosciences, 2017, 14(21) : 4985-5002. DOI: 10.5194/bg-14-4985-2017.

[71] Savvichev AS, Kokryatskaya NM, Zabelina SA et al. Microbial processes of the carbon and sulfur cycles in an ice-covered, iron-rich meromictic lake Svetloe (Arkhangelsk region, Russia). Environmental Microbiology, 2017, 19(2) : 659-672. DOI: $10.1111 / 1462-2920.13591$.

[72] Lilley MD, Baross JA, Dahm CN. Methane production and oxidation in lakes impacted by the May 18, 1980 eruption of mount st. Helens. Global Biogeochemical Cycles, 1988, 2(4) : 357-370. DOI: 10.1029/GB002i004p00357.

[73] Yang H, Xie, P, Ni LY. Underestimation of $\mathrm{CH}_{4}$ emission from freshwater lakes in China. Environmental Science and Technology, 2011, 45(10) : 4203-4204. DOI: 10.1021/es2010336.

[74] Delsontro T, Beaulieu JJ, Downing JA. Greenhouse gas emissions from lakes and impoundments: Upscaling in the face of global change. Limnology and Oceanography Letters, 2018, 3(3) : 64-75. DOI: 10.1002/lol2.10073.

[75] Boehrer B, Schultze M. Stratification of lakes. Reviews of Geophysics, 2008, 46(2). DOI: 10.1029/2006RG000210.

[76] Mayr MJ, Zimmermann M, Dey J et al. Growth and rapid succession of methanotrophs effectively limit methane release during lake overturn. Communications Biology, 2020, 3(1). DOI: 10.1038/s42003-020-0838-z.

[77] Martinez-Cruz K, Sepulveda-Jauregui A, Walter Anthony KW et al. Geographic and seasonal variation of dissolved methane and aerobic methane oxidation in Alaskan lakes. Biogeosciences, 2015, 12(15) : 4595-4606. DOI: 10.5194/bg12-4595-2015.

[78 ] Roland FAE, Morana C, Darchambeau F et al. Anaerobic methane oxidation and aerobic methane production in an east African great lake (Lake Kivu). Journal of Great Lakes Research, 2018, 44(6) : 1183-1193. DOI: 10.1016/j.jglr.2018. 04.003 . 
[79] Utsumi M, Nojiri Y, Nakamura T et al. Oxidation of dissolved methane in a eutrophic, shallow lake: Lake Kasumigaura, Japan. Limnology and Oceanography, 1998, 43(3) : 471-480. DOI: 10.4319/lo.1998.43.3.0471.

[80] Marotta H, Pinho L, Gudasz C et al. Greenhouse gas production in low-latitude lake sediments responds strongly to warming. Nature Climate Change, 2014, 4(6) : 467-470. DOI: 10.1038/NCLIMATE2222.

[81] Bange HW, Bergmann K, Hansen HP et al. Dissolved methane during hypoxic events at the Boknis Eck Time Series Station (Eckernförde Bay, SW Baltic Sea). Biogeosciences Discussions, 2009, 6(6) : 11463-11477.

[82] Barbosa PM, Farjalla VF, Melack JM et al. High rates of methane oxidation in an Amazon floodplain lake. Biogeochemistry, 2018, 137(3) : 351-365. DOI: 10.1007/s10533-018-0425-2.

[83] Deutzmann JS, Schink B. Anaerobic oxidation of methane in sediments of lake constance, an oligotrophic freshwater lake. Applied and Environmental Microbiology, 2011, 77(13) : 4429-4436. DOI: 10.1128/AEM.00340-11.

[84] Blees J, Niemann H, Wenk CB et al. Micro-aerobic bacterial methane oxidation in the chemocline and anoxic water column of deep south-Alpine Lake Lugano (Switzerland). Limnology and Oceanography, 2014, 59(2) : 311-324. DOI: 10. 4319/lo.2014.59.2.0311.

[85] Kojima H, Iwata T, Fukui M. DNA-based analysis of planktonic methanotrophs in a stratified lake. Freshwater Biology, 2009, 54(7) : 1501-1509. DOI: 10.1111/j.1365-2427.2009.02199.x.

[86] Oswald K, Graf JS, Littmann S et al. Crenothrix are major methane consumers in stratified lakes. ISME Journal, 2017,11 (9) : 2124-2140. DOI: 10.1038/ismej.2017.77.

[87] Zigah PK, Oswald K, Brand A et al. Methane oxidation pathways and associated methanotrophic communities in the water column of a tropical lake. Limnology and Oceanography, 2015, 60(2) : 553-572. DOI: 10.1002/lno.10035.

[88] Valentine DL, Reeburgh WS. New perspectives on anaerobic methane oxidation. Environmental Microbiology, 2000,2 ( 5 ) : 477-484. DOI: 10.1046/j.1462-2920.2000.00135.x.

[89] Battin TJ, Luyssaert S, Kaplan LA et al. The boundless carbon cycle. Nature Geoscience, 2009, 2(9) : 598-600. DOI: $10.1038 /$ ngeo618

[90] Shelley F, Ings N, Hildrew AG et al. Bringing methanotrophy in rivers out of the shadows. Limnology and Oceanography, 2017, 62(6) : 2345-2359. DOI: 10.1002/lno.10569.

[91] Matoušu A, Rulík M, Tušer M et al. Methane dynamics in a large river: a case study of the Elbe River. Aquatic Sciences, 2018, 81(1). DOI: 10.1007/s00027-018-0609-9.

[92] Bednařík A, Blaser M, Matoušu A et al. Sediment methane dynamics along the Elbe River. Limnologica, 2019, 79. DOI: 10.1016/j.limno.2019.125716.

[93] Musenze RS, Fan L, Grinham A et al. Methane dynamics in subtropical freshwater reservoirs and the mediating microbial communities. Biogeochemistry, 2016, 128(1/2) : 233-255. DOI: 10.1007/s10533-016-0206-8.

[94] Lopes F, Viollier E, Thiam A et al. Biogeochemical modelling of anaerobic vs. aerobic methane oxidation in a meromictic crater lake (Lake Pavin, France). Applied Geochemistry, 2011, 26(12) : 1919-1932. DOI: 10.1016/j.apgeochem.2011. 06.021 .

[95] Lofton DD, Whalen SC, Hershey AE. Effect of temperature on methane dynamics and evaluation of methane oxidation kinetics in shallow Arctic Alaskan lakes. Hydrobiologia, 2013, 721(1) : 209-222. DOI: 10.1007/s10750-013-1663-x.

[96] Hofmann H. Spatiotemporal distribution patterns of dissolved methane in lakes: How accurate are the current estimations of the diffusive flux path? Geophysical Research Letters, 2013, 40(11) : 2779-2784. DOI: 10.1002/grl.50453.

[97] Houser JN. Water color affects the stratification, surface temperature, heat content, and mean epilimnetic irradiance of small lakes. Canadian Journal of Fisheries and Aquatic Sciences, 2006, 63(11) : 2447-2455. DOI : 10.1139/F06-131.

[98] Saengkerdsub S, Ricke SC. Ecology and characteristics of methanogenic archaea in animals and humans. Critical Reviews in Microbiology, 2014, 40(2) : 97-116. DOI: 10.3109/1040841X.2013.763220.

[99] Saunois M, Bousquet P, Poulter B et al. The global methane budget 2000-2012. Earth System Science Data, 2016,8 (2) : 697-751. 10.5194/essd-8-697-2016.

[100] Mcdonald IR, Hall GH, Pickuy RW. Methane oxidation potential and preliminary analysis of methanotrophs in blanket bog peat using molecular ecology techniques. FEMS Microbiology Ecology, 1996, 21: 197-211. DOI: 10.1016/S0168-6496 (96) 00056-6.

[101] Mcdonald IR, Murrell JC. The particulate methane monooxygenase gene pmoA and its use as a functional gene probe for 
methanotrophs. FEMS Microbiology Letters, 1997, 156(2) : 205-210. DOI: 10.1111/j.1574-6968.1997.tb12728.x.

[102] Chen Y, Dumont MG, Neufeld JD et al. Revealing the uncultivated majority: Combining DNA stable-isotope probing, multiple displacement amplification and metagenomic analyses of uncultivated Methylocystis in acidic peatlands. Environmental Microbiology, 2008, 10(10) : 2609-2622. DOI: 10.1111/j.1462-2920.2008.01683.x.

[103] Chen Y, Dumont MG, Mcnamara NP et al. Diversity of the active methanotrophic community in acidic peatlands assessed by mRNA and SIP-PLFA analyses. Environmental Microbiology, 2008, 10(2) : 446-459. DOI: 10.1111/j.1462-2920. 2007.01466.x.

[104] Kip N, Ouyang WJ, Van Winden J et al. Detection, isolation, and characterization of acidophilic methanotrophs from sphagnum mosses. Applied and Environmental Microbiology, 2011, 77(16) : 5643-5654. DOI: 10.1128/AEM.05017-11.

[105] Yun JL, Zhuang GQ, Ma AZ et al. Community structure, abundance, and activity of methanotrophs in the Zoige Wetland of the Tibetan Plateau. Microbial Ecology, 2011, 63(4) : 835-843. DOI: 10.1007/s00248-011-9981-x.

[106] Holgerson MA. Drivers of carbon dioxide and methane supersaturation in small, temporary ponds. Biogeochemistry, 2015, 124(1/2/3) : 305-318. DOI: $10.1007 /$ s10533-015-0099-y.

[107] Natchimuthu S, Selvam BP, Bastviken D. Influence of weather variables on methane and carbon dioxide flux from a shallow pond. Biogeochemistry, 2014, 119(1-3) : 403-413. DOI: 10.1007/s10533-014-9976-z.

[108] Chen Y, Dong SL, Wang F et al. Carbon dioxide and methane fluxes from feeding and no-feeding mariculture ponds. Environmental Pollution, 2016, 212 : 489-497. DOI: 10.1016/j.envpol.2016.02.039.

[109] Yang P, Zhang YF, Yang H et al. Ebullition was a major pathway of methane emissions from the aquaculture ponds in southeast China. Water Research, 2020, 184: 116-176. DOI: 10.1016/j.watres.2020.116176.

[110] Bastviken D, Cole J, Pace M et al. Methane emissions from lakes: Dependence of lake characteristics, two regional assessments, and a global estimate. Global Biogeochemical Cycles, 2004, 18(4). DOI: 10.1029/2004GB002238.

[111] Deemer BR, Harrison JA, Li SY et al. Greenhouse gas emissions from reservoir water surfaces: A new global synthesis. Bioscience, 2016, 66(11) : 949-964. DOI: 10.1093/biosci/biw117.

[112] Zhu YZ, Purdy KJ, Eyice O et al. Disproportionate increase in freshwater methane emissions induced by experimental warming. Nature Climate Change, 2020, 10(7). DOI: 10.1038/s41558-020-0824-y.

[113] Oh Y, Zhuang QL, Liu LC et al. Reduced net methane emissions due to microbial methane oxidation in a warmer Arctic. Nature Climate Change, 2020, 10(4). DOI: 10.1038/s41558-020-0734-z.

[114] Morana C, Borges AV, Roland FAE et al. Methanotrophy within the water column of a large meromictic tropical lake (Lake Kivu, East Africa). Biogeosciences, 2015, 12(7) : 2077-2088. DOI: 10.5194/bg-12-2077-2015.

[115] Oswald K, Milucka J, Brand A et al. Aerobic gammaproteobacterial methanotrophs mitigate methane emissions from oxic and anoxic lake waters. Limnology and Oceanography, 2016, 61(S1) : S101-S118. DOI: 10.1002/lno.10312.

[116] Sawakuchi HO, Bastviken D, Sawakuchi AO et al. Oxidative mitigation of aquatic methane emissions in large Amazonian rivers. Global Change Biology, 2016, 22(3) : 1075-1085. DOI: 10.1111/gcb.13169.

[117] Bastviken D, Ejlertsson J, Sundh I et al. Methane as a source of carbon and energy for lake pelagic food webs. Ecology, 2003, 84(4) : 969-981. DOI: 10.1890/0012-9658(2003) 084[0969: MAASOC]2.0.CO;2.

[118] Brankovits D, Pohlman JW, Niemann H et al. Methane- and dissolved organic carbon-fueled microbial loop supports a tropical subterranean estuary ecosystem. Nature Communications, 2017, 8: 1835. DOI: 10.1038/s41467-017-01776-x.

[119] Schilder J, Van Hardenbroek M, Bodelier P et al. Trophic state changes can affect the importance of methane-derived carbon in aquatic food web. Proceedings of the Royal Society B-Biological Sciences, 2017, 284(1857). DOI: 10.1098/rspb. 2017.0278.

[120] Sanseverino AM, Bastviken D, Sundh I et al. Methane carbon supports aquatic food webs to the fish level. PLoS One, 2012, 7(8). DOI: 10.1371/journal.pone.0042723. 